\title{
THE IMPACT OF DIFFERENT CLEANING PROTOCOLS ON RESIN BOND STRENGTH TO POLYMER-INFILTRATED CERAMIC MATERIAL
}

\author{
Shaimaa Ahmed Abo El-Farag*
}

\begin{abstract}
Purpose: This study measured and compared shear bond strength (SBS) of a composite resin cement with that of PICN material after different surface cleaning methods.

Materials and Methods: Forty Vita-Enamic plates $(10 \times 7 \times 2 \mathrm{~mm})$ were fabricated using of a low speed, water-cooled diamond saw. All plates were air-borne particle abraded using $50 \mu \mathrm{m}$ $\mathrm{Al}_{2} \mathrm{O}_{3}$ then contaminated with saliva, after that all plates were classified into four groups $(\mathrm{n}=10)$ : control group (CG) in which conventional cleaning with air-water spray was used, and three test groups as follow: ultrasonic cleaning (UCG), steam cleaning (SCG), Ivoclean cleaning (ICG). Composite resin discs (Nexcomp) were cemented to ceramic plates using self-adhesive resin cement (Supercem). All bonded specimens were stored in $37^{\circ} \mathrm{C}$ water for 1 month then, thermocycled 1000 times in water baths between $5^{\circ} \mathrm{C}$ and $55^{\circ} \mathrm{C}$. Shear bond strength (SBS) test was performed using a universal testing machine. Scanning Electron Microscope (SEM) was used for failure mode examination.
\end{abstract}

Results: Different cleaning methods significantly increased SBS values of tested groups compared to control one $(\mathrm{p}=0.000)$. The highest mean SBS (MPa) was reported for (SC) test group $(18.41 \pm 1.5 \mathrm{MPa})$ followed by (UC) test group $(11.52 \pm .99 \mathrm{MPa})$. While the lowest mean SBS was observed for (CG) (4.00 $\pm .59 \mathrm{MPa})$. There was statistically significant difference between (SCG) and other groups (CG, UCG, ICG) $(\mathrm{p}=0.0001)$. There was no statistically significant difference between IC and UC test groups ( $\mathrm{p}=0.2941)$.

Conclusion: Within the limitation of the present study, the bond strength of self-adhesive resin cement to hybrid ceramics increased by different surface cleaning protocols.

KEYWORDS: Polymer infiltrated ceramics, cleaning techniques, saliva contamination, bond strength, resin cement.

* Associate Professor, Fixed Prosthodontics Dept, Faculty of Dentistry, Mansoura University and Horus University (HUE), Egypt. 


\section{INTRODUCTION}

Dental ceramics are widely used as biomaterials in prosthetic dentistry because of their attractive clinical properties. Ceramic materials have been developed and introduced in dentistry for many years as they are esthetically pleasing and chemically stable. Most ceramics are characterized by their chemical inertness, high wear resistance, superior hardness, low to moderate fracture toughness, biocompatibility and susceptibility to tensile fracture.(1)

Many factors must be taken into consideration for success and long life span of any indirect restorations, these factors can be summarized as: preparation coarseness/design, provisional cementation, methods of cleansing, fitness of final restoration, and type of the permanent luting material. ${ }^{(2)}$

Selection of restorative material is considered an important point to be concern. The high similarity between mechanical properties of both the selected restorative material and sound tooth structure has favorable effect on restorative system reliability. Polymer infiltrated ceramic material has been developed recently to combine positive characteristic of both composite and ceramic. ${ }^{(3)}$

Polymer infiltrated ceramic material (PICM) (Vita Enamic) is recently developed by Vita (VITA Zahnfabrik, Bad Säckingen,Germany). ${ }^{(4)}$ It is manufactured depending on infiltration of presintered ceramic network (In-Ceram System) which was released by Vita in the 90's ${ }^{(5,6)}$ with a lowviscosity acrylate polymer network by capillary action. ${ }^{(7)}$ It was noticed that, the difference between the resin and glass infiltration into porous ceramic was a significant. This difference may be related to a mount of final shrinkage following polymer infiltration that occurred after cooling is nearly $5 \%$, much greater glass infiltration which is $1 \% .^{(5,8)}$

PICM is being indicated for many types of restorations such as: single crowns, inlays, onlays, and veneers because of an motivating equilibration between strength and elasticity related to both ceramic and composites. ${ }^{(5)}$ The combination of ceramic and polymer phases improve the material stability, elasticity, hardness and flexural strength to simulate natural tooth structure. ${ }^{(6,7,9)}$ The strength of polymeric part is less than $30 \mathrm{MPa}$, while the strength of ceramic network is about $160 \mathrm{MPa}$, whereas the strength of final PICM is of $135 \mathrm{MPa} .{ }^{(5)}$ The properties are in-between those of particle-filled resins and ceramics as expectant for a composite material. ${ }^{(4,5,10)}$

The initial inspection of a PICM demonstrated that the flexural strength of infiltrated ceramic was greater than the fully sintered ceramic or the pure polymer. Also the flexural strength of Polymer infiltrated ceramics is approximately $150 \mathrm{MPa}$. (11,12) Vita Enamic material showed lower flexural strength than that of IPS e.max as lithium disilicate glass-ceramic material (342 MPa). ${ }^{(13)}$

Low elastic modulus and inert biaxial flexural strength of the Vita Enamic material might cause its clinical fracture when contrasted with other fired ceramic frameworks. ${ }^{(14,15)}$ These fractures can be repaired easily by composite resins. ${ }^{(5,8)}$ Research works on the best methodology and longevity of hybrid ceramics repairs are inconsiderable so, the adhesion of composite resin repairs to the polymerinfiltrated ceramic network substrate still needs to be examined. ${ }^{(14)}$ Repair process allows saving time and resources, diminishing microbial adhesion to the fracture and, thus, preserving the dental remainder. (14,16) Until now the instancy for a new restoration should be taken into considerations.

There are many difficulties that may occur during bonding of restorative materials, the most common problem is contamination that decreases the bond strength values. ${ }^{(17)}$ The bonding surfaces of ceramic restorations are often expose to contamination during routine dental procedures. ${ }^{(\mathbf{1 8 , 1 9})}$ There are numerous sources of oral contamination that can 
be classified into: 1) intrinsic and microscopic like bacteria and intrinsic and macroscopic like blood, saliva and oral fluids, 2) extrinsic that produced from the materials introduced into the oral cavity from diet, beverages and extrinsic introduced by the dentist like lubricants used with rotatory instruments, silicone indicators and latex. ${ }^{(20)}$

The main content of the oral cavity is saliva that has great effect on the bonding areas. It is composed of $99.4 \%$ water and $0.6 \%$ solids, these solids are combination of organic particles, inorganic particles and macromolecules. ${ }^{(21)}$ Salivary components are easily absorbed by acid conditioned tooth surface, that reduces the surface energy leaving nonbondable surface. An essential requirement for strong adhesive bonds is that the fitting surface must be clean and should maintain high level of energy. Films of organic debris and water may interfere with the intaglio surface wetting and spreading. ${ }^{(22)}$

Study performed by Zortuk et al., (2010) $)^{(23)}$ demonstrated that, saliva contamination of glass ceramics causing a massive decrease in surface energy. Therefore, the effectiveness of bonding ability of ceramic surfaces to resin cement materials was reported. Although, they explained that, ceramic surfaces were the least susceptible to plaque accumulation and pellicle formation among all dental restorative materials. Improper cleaning of the contaminations increase the risk of all ceramics failure. ${ }^{(24)}$

Different protocols can be used for cleaning of ceramic surfaces, one of these methods is water washing but Soares et al., (2007) ${ }^{(25)}$ and Raffaini et al., (2008) $)^{(26)}$ stated that, an incomplete recovery of bond strength resulted when utilizing water washing. Chang et al., (2010) ${ }^{(27)}$ confirmed the previous results that water rinsing was insufficient as a cleaning method due to higher blood protein molecules which resisted water washing and inhibiting adhesive infiltration.

Saliva-protein contamination are still main problems during bonding of ceramic restorations.
Using of different organic solutions to remove the saliva contamination on luting surface of restoration before cementation is recommended method. ${ }^{(28)}$ The composition of used cleaning agents should not cause any destructions to the restoration surface and improve adhesive ability of dental restorative materials. On the other hand, it should be applied simply, washed off easily, non-toxic chemicals and has no negative effects on the restoration adaptation. Many researches have performed on various cleansing techniques for instance, water washing, alcohol (70\%-96\% isopropanol), phosphoric acid $(37 \%)^{(29,30)}$, and further airborne particle abrasion $\left(\mathrm{Al}_{2} \mathrm{O}_{3}\right) \cdot{ }^{(31)}$

Novel cleaning material called Ivoclean, is an alkaline suspension of zirconium oxide particles, was developed to clean the contaminated restoration surfaces and improve bonding to resin cements ${ }^{(32)}$, but there is a little information regarding to use and effect of this agent. Therefore, the current study was designated to evaluate the effect of different cleaning methods on the contaminated surface of hybrid ceramic and the shear bond strength of resin cement to this ceramic. The null hypothesis was that different cleaning protocols have no effect on shear bond strength to hybrid ceramic.

\section{MATERIALS \& METHODS}

Materials used in this study and their basic compositions are shown in (Table 1). For this in-vitro study, forty plates of Vita Enamic ceramic were prepared from polymer infiltrated ceramics (VITA ENAMIC blocks 3M2-HT-EM-14,VITA-Zahnfabrik, Bad Säckingen, Germany) into the dimensions ( $10 \mathrm{mmX} 7 \mathrm{~mm}$ and $2 \mathrm{~mm}$ in thickness) by aid of a low speed, water-cooled diamond saw (Isomet 4000, buchler 1td, Lake Bluff, IL, USA). ${ }^{(33)}$ All plates were inspected under microscope for presence of any cracks, then treated with air-borne particle abrasion using $50 \mu \mathrm{m} \mathrm{Al}_{2} \mathrm{O}_{3}$ (Basic Eco SandBlaster, Renfert, Hilzingen, Germany ), under 2.5 bars pressure for 
TABLE (1): Description of materials utilized in the study.

\begin{tabular}{|c|c|c|c|c|}
\hline Material & Composition & Product Description & Manufacturer & $\begin{array}{c}\text { Lot } \\
\text { number }\end{array}$ \\
\hline Vita Enamic. & $\begin{array}{l}\text { Polymer infiltrated ceramic, } \mathrm{SiO} 2(58-63) \text {, } \\
\mathrm{A} 12 \mathrm{O} 3(20-23), \mathrm{Na} 2 \mathrm{O}(9-11), \mathrm{K} 2 \mathrm{O}(4-6), \\
\text { B2O3 (0.5-2), } \mathrm{ZrO} 2(<1), \mathrm{KaO}(<1)\end{array}$ & $\begin{array}{l}\text { polymer infiltrated ceram- } \\
\text { ics VITA ENAMIC blocks } \\
\text { 3M2-HT-EM-14 }\end{array}$ & $\begin{array}{c}\text { VITA Zahnfabrik, } \\
\text { Spitaglasses 3, } \\
\text { D-79713 Bad } \\
\text { Säckingen, Germany }\end{array}$ & 45810 \\
\hline $\begin{array}{c}\text { Ivoclean } \\
\text { Refill }\end{array}$ & $\begin{array}{c}\text { Ideal composition (in weight } \% \text { ) } \mathrm{ZrO}_{2} 10-15 \\
\mathrm{H}_{2} \mathrm{O}_{2} 65-80 \text {. Polyethylene glycol } 8-10 \\
\mathrm{NaOH} \text { Lower than or equal } 1 \text { Pigments, addi- } \\
\text { tives } 4-5\end{array}$ & $\begin{array}{l}\text { Universal } \\
\text { cleaning paste }\end{array}$ & $\begin{array}{l}\text { Ivoclar Vivadental } \\
\text { AG, Lichtenstein }\end{array}$ & X00617 \\
\hline Monobond ${ }^{\circledR} \mathrm{N}$ & $\begin{array}{l}\text { Alcohol solution of silane methacrylate, } \\
\text { phosphoric acid methacrylate and sulphide } \\
\text { methacrylat }\end{array}$ & $\begin{array}{c}\text { Universal primer, one com- } \\
\text { ponent universal restorative } \\
\text { primer. }\end{array}$ & $\begin{array}{l}\text { Ivoclar Vivadental } \\
\text { AG, Lichtenstein }\end{array}$ & Y29210 \\
\hline $\begin{array}{l}\text { SuperCem, } \\
\text { Self-Etch } \\
\text { Self-Adhesive } \\
\text { Resin Cement }\end{array}$ & $\begin{array}{l}\text { Base: silicon dioxide, Barium glass, Bis- } \\
\text { GMA, Triethyleneglycol Dimethacrylate, } \\
\text { Diurethan- dimethacrylate. } \\
\text { Catalyst: silicon dioxide, Barium glass, Tri- } \\
\text { ethyleneglycol Dimethacrylate, Diurethan- di- } \\
\text { methacrylate, Champhorquione }\end{array}$ & $\begin{array}{c}\text { Dual cured dental resin ce- } \\
\text { ment, base and catalyst with } \\
\text { a dual syringe and mixing } \\
\text { tip. }\end{array}$ & $\begin{array}{l}\text { DentKist, Inc, Eli- } \\
\text { Dent group S.P.A. } \\
\text { KOREA. }\end{array}$ & 3020004 \\
\hline Nexcomp & $\begin{array}{c}\text { Bis-GMA, UDMA, Bis-EMA } \\
\text { Borosilicate glass }\end{array}$ & Nano hybrid composite resin & $\begin{array}{c}\text { META }{ }^{\circledR} \text { BIOMED, } \\
\text { Korea }\end{array}$ & $\begin{array}{c}\text { NXC } \\
1712112\end{array}$ \\
\hline $\begin{array}{l}\text { Ethyl Alcohol } \\
\text { (Ethanol) } \\
\text { (absolute) } \\
(90 \%)\end{array}$ & $\begin{array}{l}\text { Simple alcohol with the chemical } \\
\text { formula } \mathrm{C}_{2} \mathrm{H}_{6} \mathrm{O}\end{array}$ & $\begin{array}{l}\text { Dehydrated alcohol volatile and } \\
\text { colourless liquid. Commonly, } \\
\text { used in synthetic organic } \\
\text { reactions in both industry and } \\
\text { science. It also considered as a } \\
\text { solvent of non-polar substances. }\end{array}$ & $\begin{array}{c}\text { El Nasr } \\
\text { pharmaceutical } \\
\text { chemical company, } \\
\text { Egypt }\end{array}$ & E0058111 \\
\hline $\begin{array}{l}\text { Artificial } \\
\text { Saliva }\end{array}$ & $\begin{array}{c}700 \mathrm{mg} / \mathrm{L} \mathrm{NaCl}+1200 \mathrm{mg} / \mathrm{L}+\mathrm{KCl} 260 \mathrm{mg} / \mathrm{L} \\
+\mathrm{Na}_{2} \mathrm{HPO}_{4}+1500 \mathrm{mg} / \mathrm{L}+\mathrm{NaHCO}_{3} 330 \mathrm{mg} / \mathrm{L} \\
+\mathrm{KSCN} 1300 \mathrm{mg} / \mathrm{L}+\text { Urea }\left(\mathrm{CH}_{4} \mathrm{~N}_{2} \mathrm{O}\right) \text { of total } \\
\mathrm{PH}=6.7\end{array}$ & - & $\begin{array}{c}\text { Prepared in } \\
\text { Faculty of } \\
\text { science, Mansoura } \\
\text { University }\end{array}$ & - \\
\hline
\end{tabular}

$15 \mathrm{sec}$. and a distance of $10 \mathrm{~mm}$, and cleaned ultrasonically. All ceramic plates were inserted in (20) $\mathrm{ml}$ of artificial saliva for 3 min. $^{(34)}$ then were divided into four groups $(n=10)$ : control group $(C G)$ in which conventional cleaning method with air-water spray from shipsyring was used and three test groups according to different cleaning methods used after contamination as follow: ultrasonic cleaning using 90\% ethyl alcohol (UCG), steam cleaning (SCG), and Ivoclean cleaning (ICG). Group UCG: after saliva contamination, plates were immersed in ethyl alcohol of $(90 \%)$ concentration for $10 \mathrm{~min}$. in digital ultrasonic cleaner (MCS, Egypt), followed by drying with air using oil free air for $10 \mathrm{sec}$. Group SCG: plates in this group were exposed to steam cleaning by a (steam cleaner, Tianjin, China) of 4 bar pressure and a water container of $200 \mathrm{ml}$. It works through releasing streams of steam on the contaminated plates then drying with air-free oil for $10 \mathrm{sec}$. Group ICG: Chemical cleaning with 
a commercial cleaning paste (Ivoclean). It was utilized with a brush and kept on the ceramic surface for $20 \mathrm{sec}$. then, deionized water was used for plates washing for $15 \mathrm{sec}$. and dried with air for $10 \mathrm{sec}$. according to manufacturer recommendation.

\section{Resin-Based Composite (RBC) Specimen Prepa- ration}

Forty composite blocks were fabricated by layering (3mm-thickness) increments of a Nanohybrid light-curing composite (Nexcomp shade A2, META ${ }^{\circledR}$ BIOMED, Korea) that made using plastic mold of 4 holes. Each hole has $4 \mathrm{~mm}$ internal diameter from the center and a thickness of $3 \mathrm{~mm}$. Every increment was light-cured for 40 sec. (Astralis 7; Ivoclar Vivadent, Schaan, Liechtenstein; output monitored at $600 \mathrm{~mW} \mathrm{cm-}$ 2 ). The composite blocks were eliminated from the mold, and further light-cured from all aspects for 40 sec. each on the portions previously in contact with the internal surface of the mold. RBC surfaces were sandblasted with $50 \mu \mathrm{m} \mathrm{Al}_{2} \mathrm{O}_{3}$ for $10 \mathrm{sec}$, utilizing an intraoral air abrasion apparatus at a pressure of 87 psi (Optiblast, Buffalo Dental Mfg Inc, New York, NY, USA). All blocks were inspected for any defects and cleaned using digital ultrasonic cleaner (Model: CD-4820, CODYSON, China, and Serial No: 04120122463). ${ }^{(35)}$

\section{Bonding procedures}

After cleaning of contaminated Vita Enamic plates, they were prepared to be ready for bonding to composite resin blocks according to manufacture recommendations as they were dried with moisturefree compressed air for 20sec. After that, a thin layer of Monobond N (Ivoclar Vivadental AG, Lichtenstein) was applied according to manufacture instructions with a micro-brush to the pre-treated and cleaned ceramic plates. The primer was permitted to react for $60 \mathrm{sec}$. furthermore, remaining abundance was dispersed with a gentle stream of air subsequently. Bonding procedure was performed using self-adhesive resin luting agent (SuperCem, Self-Etch Self-Adhesive Resin Cement, DentKist) which is a dual-cured dental resin cement, mixing and application of the luting cement was according to the manufacturer's guidelines. It was mixed then applied over the abraded surface of composite blocks then fully seated on the Vita Enamic plates. The excess cement was removed with a brush prior to spot curing. For standardized equal pressure during the cementation, a load of $1 \mathrm{Kg}$ was used over cemented specimens resulted in standardized uniform cement film thickness. ${ }^{(36)}$ The bonding assembly was light polymerized for $40 \mathrm{sec}$. for each surfaces from four directions at a distance of $10 \mathrm{~mm}$. After excess cement has been removed, the constant load was left for $5 \mathrm{~min}$. Before shear bond strength estimation, the specimens were stored at $37^{\circ} \mathrm{C}$ in distilled water for 30 days, then they were thermocycled for 1000 cycles in water baths between $5^{\circ} \mathrm{C}$ and $55^{\circ} \mathrm{C}$, water storage. The dwell time at each temperature was $30 \mathrm{sec}$. with a transfer time of $15 \mathrm{sec}$. between baths (Theromocycler, Robota, Alexandria, Egypt). The thermocycling conditions were based on the calculation of that 1000 thermocycles would simulate the situation during one year in the oral cavity. ${ }^{(37)}$ After thermocycling, specimens were tempered to room temperature in a water bath then shear bond strength test was performed and values were recorded in (MPa). A shearing load was applied at a $0.5 \mathrm{~mm} / \mathrm{min}$ crosshead speed. The chosen slow crosshead aimed to produce a shearing force during blocks debonding along the ceramic-resin interface. The debonding load was recorded in Newton.

\section{Shear bond strength test}

The universal testing machine (Instron Universal testing machine, model no. 3345, England) was used for shear bond strength measurement at across-head speed of $0.5 \mathrm{~mm} / \mathrm{min}$. using computer software Blue Hill Instron. It was recorded in MPa and was obtained by dividing the debonding load (N) at the time of fracture by the bonding surface 
area. Failed areas of the specimens were evaluated. Specimens were dehydrated using solutions of ethanol, air dried, fixed on metallic stubs, then covered by thin layer of gold (Sputter Coating Evaporator, SPI Module - Sputter Carbon / Gold Coater), and examined using a Scanning Electron Microscope (SEM) (JEOL JSM $6510 \mathrm{lv}$, Japan) at different magnifications. The failure modes were classified as cohesive failure; that is referred to a complete fracture within the ceramic or within the composite resin, adhesive failure; which means fracture between the ceramic (or composite resin) and bonding agent, and mixed fracture; which indicates fracture involving two materials.

\section{RESULTS}

The obtained results were subjected to statistical analysis by SAS computer program (Version 9.1.3. SAS Inst., Cary, NC.) using the general linear models (GLM). Data were presented as mean \pm SD. Test groups were compared by One-way analysis of variance (ANOVA) and the significance of the mean difference between the groups were done by Tukey's multiple comparison test at ( $\mathrm{p} \leq 0.05)$. In the current study it was found that, the highest mean SBS (MPa) was reported for steam cleaning group (18.411 MPa), while the lowest mean SBS value was observed for control group (4.000 MPa). There was no statistically significant difference between ultrasonic and Ivoclean cleaning groups (11.525 $\mathrm{MPa}, 10.989 \mathrm{MPa})$ respectively $(\mathrm{P}=0.2941)$. On the other hand there was high statistically significant difference between (SCG) and other groups (CG, UCG, ICG) $(\mathrm{p}=0.0001)$. (Table 2)

\section{Scanning Electron Microscopy (SEM)}

In this in-vitro study, failure pattern was evaluated using SEM at different magnifications as shown in (Table 3). Failure pattern of all debonded specimens showed mainly mixed failure in which adhesive failure occurred between Vita-enamic ceramic and cement with remnants of resin cement adherent to the ceramic plates. On the other hand some of specimens showed completely adhesive failure between ceramic and resin cement as the specimen surface was free from any remnants of resin cement. (Fig. 1)

TABLE (2): Mean and standard deviations of shear bond strength in (Mpa) of all test groups

\begin{tabular}{|c|c|c|}
\hline GROUP & Mean & SD \\
\hline CG & $4.000^{\mathrm{c}}$ & 0.597 \\
\hline UCG & $11.525^{\mathrm{b}}$ & 0.998 \\
\hline SCG & $18.411^{\mathrm{a}}$ & 1.565 \\
\hline ICG & $10.989^{\mathrm{b}}$ & 1.126 \\
\hline P value & \multicolumn{2}{|c|}{0.0001} \\
\hline
\end{tabular}

$a-c=$ Means with the same letter in the column are not significantly different at $\mathbf{P} \leq \mathbf{0 . 0 5}$.

TABLE (3): Failure patterns of different tested groups.

\begin{tabular}{|c|c|c|c|}
\hline \multirow{2}{*}{$\begin{array}{c}\text { Cleaning } \\
\text { methods }\end{array}$} & \multicolumn{3}{|c|}{ Failure modes } \\
\cline { 2 - 4 } & Adhesive & Mixed & Cohesive \\
\hline CG & 5 & 5 & 0 \\
\hline UCG & 3 & 7 & 0 \\
\hline SCG & 2 & 8 & 0 \\
\hline ICG & 3 & 7 & 0 \\
\hline
\end{tabular}




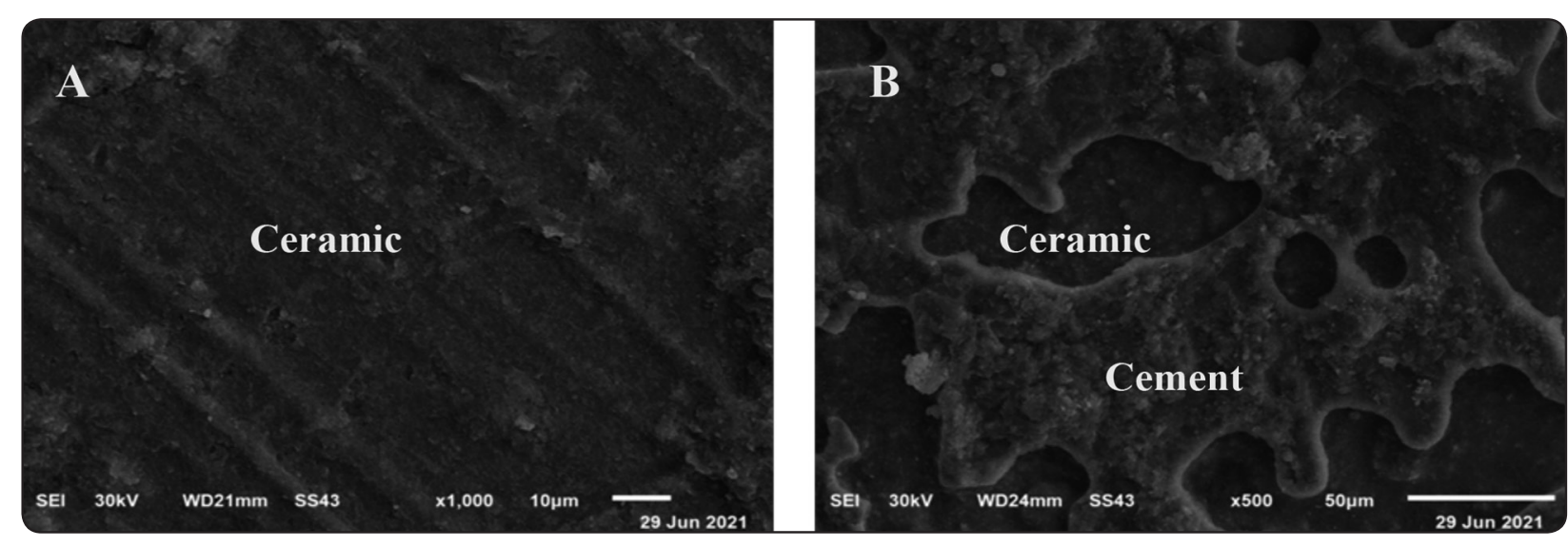

Fig. (1) SEM image showing: A) adhesive failure at composite/ceramic disc interface. B) mixed mode of failure after debonding procedures.

\section{DISSCUSION}

This in-vitro study aimed to assess the impact of various cleaning protocols on bond strength to contaminated hybrid ceramic surface. The null hypothesis of this research work was rejected as the cleaning methods had an essential role in improvement of bond strength values to Vita Enamic ceramic.

Vita Enamic material was chosen as it is a new type of material combines the advantages of both ceramic and composite materials and known as polymer infiltrated ceramic (PICM). According to the material composition, the presence of both polymer and ceramic phases together within used PICM results in plasticity feature to the bulk material. ${ }^{(3)}$ The polymer content of this material is consisted of two interpenetrating networks, resulting in a diminished fracture susceptibility of hybrid ceramic and increased crack resistance. ${ }^{(3,38)}$

More favorable advantages have been reported for Vita Enamic material such as the acceptable indicator of brittleness that allows the material to be manipulated in one step without requiring additional firing such as some partially sintered CAD/CAM materials. This result in final products with a higher degree of dimensional accuracy. Comparing with traditional veneering porcelains, the lower material hardness provide better protection of opposing teeth against excessive wear. $^{(3)}$

All tested groups in this study were mechanically treated using an $\mathrm{Al}_{2} \mathrm{O}_{3}$ abrasion procedure, as this micromechanical surface treatment considered an effective method for ceramic surface modification by increasing surface energy and surface area for wettability and bonding. ${ }^{(39-41)}$ On the other hand, it increases roughness of the surface and helps in penetration of resin cement into micro-retentions that creates an interlock micromechanically between the resin cements and ceramics. This method for surface treatment is controlled by certain parameters like pressure, distance from ceramic surface, particle size, impact angle, and working time. Any differences lead to contradictory results. ${ }^{(42)}$

There is no doubt that, air abrasion can be used as an effective cleaning method as it cleans the inner surface of restorations. It is considered as the most effective cleaning methods and there was a consensus from previous studies that air-borne abrasion increases the surface area and chemical activation of the bonding surface because it removes organic contaminants. ${ }^{(43)}$

In this work, universal primer was used for Vita-Enamic surface treatment before bonding as it is considered superior pretreatment in all recently available in-vitro studies. Also, it becomes more 
recommended form the International Academy for Adhesive Dentistry (IAAD). ${ }^{(44,45)}$ Monobond-N was used in this research work, as it composed of three functional methacrylate groups; silane methacrylate for glass ceramic, sulfide methacrylate for precious metal alloys, and phosphoric acid methacrylate which is the most important one as it belongs for oxide ceramics and base metal alloys. ${ }^{(46)}$

The results of this study showed that, shear bond strength values obtained from control group after salivary contamination and air-water spray cleaning were $(4.00 \pm 0.59 \mathrm{MPa})$ this proved that, using of airwater spray from shipsyring is not recommended for surface cleaning after contamination and is not sufficient to maintain stable and strong bond strength between Vita-Enamic and resin cements, this agreed with results of Bayındir and Köseoğlu study (2020). ${ }^{(47)}$

Maintaining of restorations intaglio surface free of contaminants is a challenge and provide strong bond which is very important for long term clinical durability. ${ }^{(43,48)}$ During try-in step, the bonding surfaces of ceramic restorations become contaminated with saliva, silicone indicators and blood. The methods of cleaning depending on type of contamination. ${ }^{(24,49)}$ The most common cause of reduction of restoration bond strength is saliva contamination. It affects resin bonding to ceramic negatively as it leaves behind an organic adhesive layer in the early few seconds of the exposure which is washing resistance. ${ }^{(50)}$

Physiological saliva consists of $99 \%$ water, proteins, little amount of sugar, glycoprotein, amylase, and inorganic particles. Adsorption of salivary proteins occurs on the surface of restorative materials after contamination with saliva, leaving a thin layer of organic protein bio-film that is resistant to water washing. ${ }^{(34)}$ Most of inorganic components, such as phosphate and calcium, present in artificial but does not contain any human salivary proteins. In this study artificial saliva was used because using of human saliva in research work may lead to disturbance in standardization and reproducibility of experiments due to human difference as reported by Joukhadar et al., (2020) ${ }^{(48)}$

Previous studies explained the role of cleaning methods in enhancement of bond strength to ceramic restorations so, many different cleaning protocols were applied. ${ }^{(43)}$ There are many factors control the choice of these methods for example, duration from exposure to contamination, type of contamination, surface area exposed to contaminants and the effectiveness of the cleaning method. ${ }^{(50)}$ In the present study cleaning methods and materials can overcome the adverse effect of saliva contamination on ceramic, but this effect differs depending on the cleaning method.

One of cleaning agents used in this study is a chemical cleaning paste called Ivoclean that consisted of an alkaline suspension of zirconium oxide particles. It is also containing zirconia, water, sodium hydroxide, polyethylene glycol and other components. Regarding to concentration of particles and size in its composition, Ivoclean acts as a "sponge" as phosphate contaminants from saliva absorbed by its particles than any other ceramic surfaces and leaves ceramic clean and free from any debris. The current research illustrated that, both Ivoclean and ultrasonic cleaning groups showed high SBS than control group. This finding may be related to high $\mathrm{pH}$ level of Ivoclean, which might be necessary for enhancement of bond strength when combined with universal primer. ${ }^{(24,43)}$ Also according to scientific documentation, Ivoclean is a universal cleaning paste that can be used with various types of dental restorative materials and it creates the basis for strong and stable bond between the adhesive resin cement and restorations. ${ }^{(51)}$

An ultrasonic is a common cleaning method. It was supposed to improves the bond strength levels between resin cement and ceramic surface. ${ }^{(52)}$ The idea of ultrasonic cleaning depends on "cavitation" which defined as microscopically creation of bubbles in a solution by the electrical frequency 
conversion into sound waves. These bubbles break down debris to the molecular level and remove them away from contaminated surfaces. ${ }^{(53)}$ Cleaning solutions for ultrasonic cleaners may be any type of liquid to be used according to manufacturer recommendations so, in this study ethyl alcohol of $(90 \%)$ concentration was used. However, the effect of ultrasonic cleaning is argumentative, the result of this study disagreed with Nishigawa et al., $(2016)^{(54)}$ who reported that, cleaning of dental restorations using ultrasonic cleaner after sandblasting should be avoided because it decreased the adhesive strength of resin luting material. Also, Passos et al., (2010) ${ }^{(55)}$ concluded that ultrasonic cleaning with isopropanol might lead to low values of bond strengths and unstable bond.

In the current study it was found that, the highest mean SBS (MPa) was reported for steam cleaning group (18.411 MPa). The commonly used method in dental laboratories is steam cleaners for cleaning impression trays and models, removing polishing debris, and removing metal frames and wax. Steam cleaning after sandblasting is considered a simple and easy way to remove any debris. Application of steam cleaning had an improving effect on bond strength of restorations with less adhesive failure. (56) However, using of this method is controversial, so, it should be used with caution during surface cleaning of dental restorative materials. Extra use of the steam cleaning on ceramic surface subsequent to sandblasting could make the surface configuration clear in SEM by eliminating some sandblasted particles loosely embedded in surface as well as the debris and oily contaminants. The resultant bond strength was significantly improved to reach almost the maximum bond strength of this ceramiccomposite assembly. ${ }^{(56)}$

Dental restorations expose to continuous chemical, thermal, and mechanical stresses in the oral cavity. Artificial aging methods are performed to simulate these conditions in the experimental studies and to expect the durability and long-term bonding behavior. The common types of artificial aging treatment methods are water storage and thermal cycling. In this study, 1000 thermocycles were performed to simulate intra-oral environmental aging conditions. According to previous study, water storage represents a hydrolytic degradation while thermocycling represents a hydrothermal aging. Thermocycling highly affected the durability of the resin bond strength to ceramic than did water storage at a constant temperature. ${ }^{(57)}$

The analysis of the failure mode patterns showed that nearly most of failure modes that occurred at the ceramic/resin interface showed mixed mode of failure. Most of previous studies agreed with the results of the current study as the cleaned ceramic surface characterized by smooth surface appearance and predominantly mixed failure mode pattern. $(43,53,56)$

\section{CONCLUSIONS}

Within the limitations of this in vitro study, the following conclusions were drawn:

- Surface cleaning methods are recommended to improve bonding to Vita- enamic hybrid ceramic.

- Steam cleaning method was the most effective one compared to other methods.

\section{REFERENCES}

1. Denry I, Holloway J. Ceramics for dental applications: A review. Materials 2010; 3: 351-368.

2. Grasso CA, Caluori DM, Goldstein GR, Hittelman E. In vivo evaluation of three cleansing techniques for prepared abutment teeth. J Prosthet Dent 2002; 88:437-441.

3. Taha D, Spintzyka S, Schille C, Sabetb A, Wahsh M, Salah $\mathrm{T}$, et al. Fracture resistance and failure modes of polymer infiltrated ceramic endocrown restorations with variations in margin design and occlusal thickness. J Prosthodont Res 2018;62:293-297.

4. Coldea A, Swain MV, Thiel N. Mechanical properties of polymer-infiltrated ceramic- network materials. Dent Mater J 2013;29:419-445. 
5. Silva L ,Lima E , Miranda R, Favero S, Lohbauer U, Cesar P. Dental ceramics: a review of new materials and processing methods. Braz Oral Res 2017;31:133-146.

6. He LH, Swain M. A novel polymer infiltrated ceramic dental material. Dent Mater J 2011;27:527-561.

7. Sonmez N, Gultekin P, Turp V, Akgungor G, Sen D, Mijiritsky E. Evaluation of five CAD/CAM materials by microstructural characterization and mechanical tests: a comparative in vitro study. BMC Oral Health 2018; 18:1-13.

8. Chirumamilla G, Goldstein CE, Lawson NC. A 2-year retrospective clinical study of enamic crowns performed in a private practice setting. J Esthet Restor Dent 2016;28:231-238.

9. Zimmermann M, Mehl A, Reich S. New CAD/CAM materials and blocks for chairside procedures. Int J Comp Dent 2013;16:173-254.

10. Shetty R, Shenoy K, Dandekeri S, Suhaim KS, Ragher M, Francis J. Resin-matrix ceramics: an overview. Int J Rec Sci Res 2015;6:7414-7431.

11. Spitznagel FA, Scholz KJ , Strub JR , Vach K , Gierthmuehlen PC. Polymer-infiltrated ceramic CAD/ CAM inlays and partial coverage restorations: 3-year results of a prospective clinical study over 5 years. Clinical Oral Investigations 2018;22:1973-1983.

12. Chavali R, Nejat AH, Lawson NC. Machinability of CADCAM materials. J Prosthet Dent 2016;118:194-199.

13. Leung BT, Tsoi JK, Matinlinna JP, Pow EH. Comparison of mechanical properties of three machinable ceramics with an experimental fluorophlogopite glass ceramic. J Prosthet Dent 2015;114:440-446.

14. Silva P, Martinelli-Lobo CM, Bottino MA, De Melo RM, VALANDRO LF. Bond strength between a polymerinfiltrated ceramic network and a composite for repair: effect of several ceramic surface treatments. Braz Oral Res 2018;32:1-9.

15. Ramos NC, Campos TM, Paz IS, Machado JP, Bottino MA, Cesar PF, et al. Microstructure characterization and SCG of newly engineered dental ceramics. Dent Mater J 2016;32:870-878.

16. Queiroz JR, Souza RO, Nogueira Junior L Jr, Ozcan M, Bottino MA. Influence of acid-etching and ceramic primers on the repair of a glass ceramic. Gen Dent J 2012; 60:79-85
17. Nair P, Hickel R, Ilie N. Adverse effects of salivary contamination for adhesives in restorative dentistry. A literature review. Am J Dent. 2017; 30: 156-164.

18. Mageshwari M, Rahul GR, Karunakar S. A comparative study to evaluate the effect of cleaning solutions on surface characterization of saliva contaminated lithium disilicate ceramic using scanning electron microscope. an in-vitro study. Inter J Current Res. 2017; 9: 53160-53172.

19. Krifka S, Preis V, Rosentritt M. Effect of decontamination and cleaning on the shear bond strength of high translucency zirconia. Dent J. 2017; 5: 32.

20. Van Schalkwyk JH, Botha FS, van der Vyver PJ, de Wet FA, Botha SJ. Effect of biological contamination on dentine bond strength of adhesive resins. SADJ. 2003; 58: 143-147.

21. Eriksson SO, Pereira PN, Swift EJJr, Heymann HO, Sigurdsson A, Effects of saliva contamination on resin -resin bond strength. Dent Mater. 2004; 20: 37-44.

22. Tzanakakis EG, Tzoutzas IG, Koidis PT. Is there a potential for durable adhesion to zirconia restorations? A systematic review. J Prosthet Dent. 2016; 115: 9-19.

23. Zortuk M, Kilic K, Gurbulak AG, Kesim B, Uctasli S. Tensile bond strength of a lithium-disilicate pressed glass ceramic to dentin of different surface treatments. Dent Mater J. 2010; 29: 418-424.

24. Aladă̆ A, Elter B, Cömlekoğlu E, Kanat B, Sonugelen M, Kesercioğlu A, et al. Effect of different cleaning regimens on the adhesion of resin to saliva-contaminated ceramics. J Prosthodont. 2014; 11: 136-145.

25. Soares CJ, Branco CA, Soares PBF, Fonseca RB, Carlo HL, Neto AJF. Effect of blood contamination during adhesive restorative procedures on dentin-resin cement shear bond strength. Braz J Oral Sci. 2007; 6: 1320-1325.

26. Raffaini MS, Gomes-Silva JM, Torres MCP, Palma-Dibb $\mathrm{RG}$, Borstto MC. Effect of blood contamination on the shear bond strength at resin/dentin interface in primary teeth. Am J Dent. 2008; 21: 159-162.

27. Chang SW, Cho BH, Lim RY, Kyung SH, Park DS, Oh TS et al. Effects of blood contamination on microtensile bond strength to dentin of three self-etch adhesives. Oper Dent. 2010; 35: 330-336.

28. Rosenstiel SO, Land MF, Fujimoto J. Contemporary fixed prosthodontics. 5th ed. St. Louis: Mosby; 2016;774. 
29. Zhang S, Kocjan A, Lehmann F, Kosmač T, Kern M. Influence of contamination on resin bond strength to nanostructured alumina-coated zirconia ceramic. Eur J Oral Sci 2010;118:396-403.

30. Nishigawa G, Maruo Y, Irie M, Oka M, Yoshihara K. Ultrasonic cleaning of silica-coated zirconia influences bond strength between zirconia and resin luting material. Dent. Mat.J. 2008; 27:842-850.

31. Feitosa SA, Patel D, Bottino MA, Özcan M, Bottino MC, Valandro LF, et al. Effect of Cleansing Methods on SalivaContaminated Zirconia-An : Evaluation of Resin Bond Durability. Oper. Dent. 2014; 39-45.

32. Brown DT, Platt JA, Srinivasan M, Bottino MC, Levon JA. Influence of saliva contamination on resin bond durability to zirconia - effect of cleaning methods, Indiana University School of Dentistry, 2015.

33. Mushashe AM, Farias IC, Gonzaga CC, da Cunha LF, Ferracane JL, Correr GM, Surface Deterioration of Indirect Restorative Materials. Brazilian Dent J. 2020; 31: 264-271.

34. Yoshida K. Influence of cleaning methods on the bond strength of resin cement to saliva-contaminated lithium disilicate ceramic. Clin Oral Invest. 2020; 24 : 2091-2097.

35. Santos MJMC, Bapoo H, Rizkalla AS, Santos GC. Effect of Dentin-cleaning Techniques on the Shear Bond Strength of Self-adhesive Resin Luting Cement to Dentin. Oper Dent 2011; 36-5: 512-520.

36. Blatz MB, Vonderheide M, Conejo J. The effect of resin bonding on long-term success of high-strength ceramics. J Dent Res. 2018 ; 97 :132-139.

37. Sailer I, Gottnerb J, Kanelb S, Hammerle CH. Randomized controlled clinical trial of zirconia-ceramic and metalceramic posterior fixed dental prostheses: a 3-year followup, Int.J. Prosthodont. 2009; 22:553-560.

38. Helvey G. The expansion of millable materials: new additions to the market increase patient care-options. Inside Dent Technol 2014;5:58-71.

39. Thammajaruk $\mathrm{P}$, Buranadham $\mathrm{S}$, Thanatvarakorn $\mathrm{O}$, Ferrari M, Guazzato M. Influence of glass-ceramic coating on composite zirconia bonding and its characterization. Dent Mater. 2019; 35: 105-113.

40. Saleh NE, Guven MC, Yildirim G, Erol F. Effect of different surface treatments and ceramic primers on shear bond strength of self-adhesive resin cement to zirconia ceramic. Niger J Clin Pract. 2019; 22 :335-341.
41. Abi-Rached FO, Martins SB, Campos JA, Fonseca RG. Evaluation of roughness, wettability, and morphology of an yttria-stabilized tetragonal zirconia polycrystal ceramic after different airborne-particle abrasion protocols. J Prosthet Dent. 2014; 112 :1385-1391.

42. Skienhe H, Habchi R, Ounsi H, Ferrari M, Salameh Z. Evaluation of the effect of different types of abrasive surface treatment before and after zirconia sintering on its structural composition and bond strength with resin cement. Biomed Res Int. 2018; $2018: 1-12$.

43. Tunc EP, Chebib N, Sen D, Zandparsa R. Effectiveness of different surface cleaning methods on the shear bond strength of resin cement to contaminated zirconia: an in vitro study. J Adhes Sci Technol. 2016; 30: 554-565.

44. Lise DP, Van EA, De Munck J, Vieira L, Baratieri LN. Microtensile Bond Strength of Composite Cement to Novel CAD/CAM Materials as a Function of Surface Treatment and Aging. Oper Dent J 2015; 42:73-81.

45. Cekic NI, Ergun G, Egilmez F, Vallittu PK, Lassila LV. .Microshear bond strength of different resin cements to ceramic/glass-polymer CAD-CAM block materials. J Prosthodont Res 2016;60: 265-273.

46. Guimarães HAB, Cardoso PC, Decurcio RA, Monteiro LJE, de Almeida LN, Martins WF, et al., Simplified Surface Treatments for Ceramic Cementation: Use of Universal Adhesive and Self-Etching Ceramic Primer. International Journal of Biomaterials 2018;1:1-7.

47. Bayındır YZ, Köseoğlu B. Effect of universal adhesives and surface treatments on shear bond strength to hybrid CAD/CAM Ceramics. Int. J. of Applied Dental Sciences 2020; 6: 500-507.

48. Joukhadar C, Osman E, Rayyan M, Shrebaty M. Comparison between different surface treatment methods on shear bond strength of zirconia (in vitro study). J Clin Exp Dent. 2020; 12: e264-e270.

49. Szep S, Schmid C, Weigl P, Hahn L, Heidemann D. Effect of the silicone disclosing procedure on the shear bond strength of composite cements to ceramic restorations. J Prosthet Dent. 2003; 89: 60-65.

50. Lapinska B, Rogowski J, Nowak J, Nissan J, Sokolowski J, Szymanska ML. Effect of surface cleaning regimen on glass ceramic bond strength. Molecules 2019; 24:1-17. doi:10.3390/molecules24030389 www.mdpi.com/journal/ molecules. 
51. Ivoclar Vivadent A. Ivoclean: Scientific Documentation. 2011.

52. Kim HJ, Kim S, You SH, Cho SG, Choi KK, Kim DS. Effects of silane treatment on salivary protein contamination during the bonding of lithium disilicate ceramic. J Adhes Sci Tech. 2020; 34: 1-13.

53. Duran F, Teke M. Design and implementation of an intelligent ultrasonic cleaning device. Intel auto Soft Comp. 2019; $25: 441-449$.

54. Nishigawa G, Maruo Y, Irie M, Maeda N, Yoshihara K, Nagaoka N, et al. Various effects of sandblasting of dental restorative materials. PLoS One. 2016; 11: 1-10.
55. Passos SP, May LG, Barca DC, Ozcan M, Bottino MA, Valandro LF. Adhesive quality of self-adhesive and conventional adhesive resin cement to Y-TZP ceramic before and after aging conditions. Oper Dent. 2010; 35 : $689-696$.

56. Wang CS, Chen KK, Tajima K, Nagamatsu Y. Effects of sandblasting media and steam cleaning on bond strength of titanium-porcelain. Dent Mater 2010; 29 : 381- 391.

57. Souza LC, Apolonio FM, Souza LP, Carrilho MRO, Saboia VPA. Stability of the adhesive interface after different artificial aging techniques. J Dent App. 2015; 2: 153-157. 